\title{
Neonatal Outcome of Induced Prematurity for Severe Preeclampsia in Four Great Kinshasa Maternities
}

\author{
Olive Yalala Ambambula1, Andy Muela Mbangama', Therese Biselele², Rashid Rahma Tozin1, \\ Dieudonné Mushengezi Sengeyi ${ }^{1}$
}

${ }^{1}$ Department of Obstetrics and Gynecology, University Clinics of Kinshasa, Kinshasa, DR Congo

${ }^{2}$ Department of Pediatrics, University Clinics of Kinshasa, Kinshasa, DR Congo

Email: droliveambambula@yahoo.fr

How to cite this paper: Ambambula, O.Y., Mbangama, A.M., Biselele, T., Tozin, R.R. and Sengeyi, D.M. (2020) Neonatal Outcome of Induced Prematurity for Severe Preeclampsia in Four Great Kinshasa Maternities. Open Journal of Obstetrics and Gynecology, 10, 1637-1643. https://doi.org/10.4236/ojog.2020.10110147

Received: September 25, 2020

Accepted: November 27, 2020

Published: November 30, 2020

Copyright ( 2020 by author(s) and Scientific Research Publishing Inc. This work is licensed under the Creative Commons Attribution International License (CC BY 4.0).

http://creativecommons.org/licenses/by/4.0/

(c) (i) Open Access

\begin{abstract}
Severe preeclampsia (SPE) is associated with fetal complications including intrauterine growth retardation (IUGR), prematurity and in utero fetal death. Its treatment remains child birth that often is planned before term. However, this attitude can lead to fetal complications related to prematurity. Several studies on preeclampsia have already been studied in the DRC and several aspects have already been realized, but to date, the neonatal outcome has not yet been addressed. Methods: This is cross-sectional study performed in four public hospitals in Kinshasa (Democratic Republic of Congo). We included 400 cases of induced prematurity (IP) for SPE; the analysis compared pregnant women who gave birth before 34 weeks of amenorrhea (WA) and those after $34 \mathrm{WA}$. The comparison of the proportions was made by the Chi-square test and the calculation of Means by the Student's test. The significance level was set at $\mathrm{P}<0.05$. Objective: To determine the frequency of induced prematurity for severe preeclampsia (SPE), to identify the indications and to evaluate neonatal outcome. Results: The IP frequency for SPE was $46.2 \%$. The retro placental hematoma was the most indication in pregnancies before 34 WA $24.9 \%$, while high blood pressure $54.5 \%$ in the after 34 WA group. In utero death was more common in pregnant women who gave birth before 34 weeks 25.4\%; chronic fetal distress was elevated in the after 34 WA group $19.5 \%$. Neonatal infection was more common in the group after 34 WA $49.4 \%$, while respiratory distress $39.6 \%$, intra and periventricular hemorrhage $19.5 \%$ and neonatal death $39.6 \%$ were more in group before $34 \mathrm{WA}$. Conclusion: Prematurity induced for SPE is related to a poor neonatal prognosis.
\end{abstract}

\section{Keywords}

Preeclampsia, Induced Prematurity, Neonatal Outcome 


\section{Introduction}

Severe preeclampsia (SPE) is associated with fetal complications including intrauterine growth retardation (IUGR), prematurity and in utero fetal death [1]. Its treatment remains childbirth that often is planned before term [2]. However, this attitude can lead to fetal complications related to prematurity [3].

According to WHO, preterm birth is defined as any childbirth occurring between 22 and 37 weeks of age [4]. In Low-income countries like the DRC, childbirth is premature when it occurs between 28 and 37 weeks of age [5]. Its prevalence varies between $60 / 1000$ and 120/1000 of live births in developed countries [4]. In Europe, it is $8 \%$ and in the USA it represents 12\% [6]. This last high rate is essentially represented by induced prematurity. In Africa, the situation is complicated, particularly in Low-income countries like those in sub-Saharan Africa, which alone account for $22 \%$ of premature births [3]. In the DRC, prematurity accounts for 15\% [5] and University Hospital of Kinshasa is 40\% [7].

We can classify prematurity in "extremely premature" when the delivery occurs before $28 \mathrm{WA}$; "high prematurity" when childbirth is between $28 \mathrm{SA}$ and 32 WA; "moderate prematurity" when the delivery occurs between 33 WA and 36 WA.

In prematurity in general, there is a problem of immaturity of all organs anatomically and functionally. Nevertheless, what is most feared are the pulmonary problems and the appearance of motor sequel following cortical attacks. Other complications may include cerebral hemorrhage, hypothermia, hypoglycemia and hypocalcaemia [2]. Prematurity in the context of SPE is generally induced (iatrogenic decided by the medical team when the continuation of the pregnancy is threatening for the mother and/or the fetus) contrary to the spontaneous prematurity (which intervenes in the context of spontaneous work delivery) [6].

Several studies on preeclampsia have already been studied in the DRC and several aspects have already been realized, but to date the neonatal outcome has not yet been addressed that is the reason why we initiate this study which aims to determine frequency of induced prematurity for SPE; to identify indications of is induced prematurity and to evaluate its neonatal prognosis.

\section{Methods}

Our study is cross-sectional, conducted in the severe preeclampsia who gave birth in the context of IP and their newborns in four public maternities in the city of Kinshasa namely: The University Hospitals of Kinshasa, the Ngaliema Clinic, the Saint Joseph Hospital and the Provincial General Hospital of Reference of Kinshasa. The study period was from January 2013 to December 2017. The women were then divided into 2 groups: those who gave birth before $34 \mathrm{WA}$ and those who gave birth after 4 WA.

\subsection{Inclusion Criteria}

We included in the study: 
- Pregnant women who had preeclampsia during the study period;

- Preterm infants born from these women from the $28^{\text {th }}$ week to the $37^{\text {th }}$ in a single fetal pregnancy.

\subsection{Exclusion Criteria}

- Pregnancies of less than 28 weeks and more than 37 completed weeks;

- All situations that may lead to prematurity: multiple pregnancies, urinary tract infection, malaria, Premature rupture of membranes (PRM), etc.

Statistical analyzes: The Student's T test was used for the comparison of the means while the Chi-square was used for the comparison of the proportions. The significance level was set at $\mathrm{P} \leq 0.05$.

\subsection{Statistical Calculations}

Data were entered using Microsoft Excel 2007 software and exported to SPSS 21.0 for analysis. For normally distributed parametric data, comparisons of averages were made using t-test and comparisons of proportions with chi-square test.

Pearson's correlation test between biologic markers was used to seek potential associations with oxidative stress. Testing was stated significant at $\mathrm{P} \leq 0.05$.

This study has been designed and financed by our own funds.

\subsection{Ethical Considerations}

This project was prepared according to the Declaration of Helsinki and was agreed by Ethics Committee of Department of Obstetrics and Gynecology, University clinics of Kinshasa.

\section{Results}

During the period from January 2013 to December 2017, 23,945 deliveries were recorded, including 2192 cases of preeclampsia (9.1\%) including 1503 cases of severe preeclampsia; and 1012 cases of preterm delivery (4.2\%). We noted 400 cases of induced prematurity for severe preeclampsia, which represents a frequency of $1.7 \%$ of all deliveries, $18.3 \%$ of cases of preeclampsia and $39.5 \%$ of cases of preterm delivery.

Table 1 shows that the mean age of the study group was $29.5 \pm 6.8$ years. The majority were married and primipara. The mean pregnancy age at diagnosis of PE was $32 \pm 3.01$ weeks. The diagnosis of severe preeclampsia was early, at 30.8 $\pm 2.7 \mathrm{WA}$ in the group of pregnant women who gave birth before $34 \mathrm{WA}$ compared to the group who gave birth after 34 WA with a highly significant difference $(P<0.001)$. Furthermore, no statistically significant difference was noted when comparing the other features.

The most frequent indications of induced prematurity were persistence of high blood pressure figures with $49.3 \%$ followed by eclampsia with $18.8 \%$ and retro placental hematoma (RPH) with $17.8 \%$. 
Table 1. Indications of Induced Prematurity (IP).

\begin{tabular}{|c|c|c|c|c|c|c|c|}
\hline \multirow{2}{*}{ Indication of IP } & \multicolumn{4}{|c|}{ Premature $\geq 34$ WA Premature $<34$ WA } & \multicolumn{2}{|c|}{ Total } & \multirow{2}{*}{$\mathrm{p}$} \\
\hline & Number & $\%$ & Number & $\%$ & Number & $\%$ & \\
\hline SPE (HBP $\nearrow)$ & 126 & 54.5 & 71 & 42 & 197 & 49.3 & \\
\hline Eclampsia & 43 & 18.6 & 32 & 18.9 & 75 & 18.8 & \\
\hline Retroplanetal hematoma & 29 & 12.6 & 42 & 24.9 & 71 & 17.8 & \\
\hline Eclamptic Prodrome & 21 & 9.1 & 15 & 8.9 & 36 & 9 & $<0.05$ \\
\hline Chronic fetal distress & 11 & 4.8 & 8 & 4.7 & 19 & 4.8 & \\
\hline Hellp Syndrome & 1 & 0.4 & 1 & 0.6 & 2 & 0.5 & \\
\hline Total & 231 & 100 & 169 & 100 & 400 & 100 & \\
\hline
\end{tabular}

$\mathrm{RPH}$ was significantly more prevalent in the gestational group who gave birth before the 34 th week of gestation $(24.9 \%$ vs. $12.6 \% \mathrm{P}<0.05)$, whereas persistence of high blood pressure in the pregnant group who delivered from the 34 th week (54.5\% vs $42 \%, \mathrm{P}<0.05)$ (Table 2 ).

Table 2. Fetal complications of severe preeclampsia.

\begin{tabular}{ccccccccc}
\hline \multirow{2}{*}{ Fetal complications } & \multicolumn{2}{c}{ Premature $\geq \mathbf{3 4}$ WA } & \multicolumn{2}{c}{ Premature $<34$ WA } & \multicolumn{2}{c}{ Total } & \multirow{2}{*}{ P } \\
\cline { 2 - 7 } & Number & $\%$ & Number & $\%$ & Number & $\%$ & \\
\hline Oligohydramnios & 64 & 27.7 & 37 & 21.9 & 101 & 25.3 & 0.114 \\
DIU & 29 & 12.6 & 43 & 25.4 & 72 & 18 & $<0.002$ \\
CFD & 45 & 19.5 & 22 & 13 & 67 & 16 & $<0.05$ \\
\hline
\end{tabular}

Oligohydramnios (25.3\%), Death in utero (DIU) (18\%) and chronic fetal distress $(16 \%)$ are the fetal most common complications of the SPE. DIU was a more common complication before $34 \mathrm{WA}(34.4 \%$ vs $12.6 \%, \mathrm{P}<0.002)$, while CFD was more found after 34 weeks $(19.5 \%$ vs $13 \%, \mathrm{P}<0.05)$.

Table 3 shows that infants born with premature labor induced had, as frequent complications, neonatal infection (40.3\%), respiratory distress $(34.5 \%)$, neonatal death $(26.5 \%)$, neonatal hypoglycemia $(21.3 \%)$ and Cerebral meningeal hemorrhage $(\mathrm{CMH})(13.5 \%)$, comparing the group of pregnant women who gave birth prematurely from the 34 th week to those who gave birth before 34 weeks, only neonatal infection was significantly more common in the first group (49.4\% vs $27.8 \%, \mathrm{P}<0$. 001) while neonatal complications significantly more frequent in the second group were respiratory distress $(39.6 \%$ vs $30.7 \% \mathrm{P}<0.05)$, neonatal death $(39.6 \%$ vs $16.9 \%, \mathrm{P}<0.001)$ and cerebral meningeal hemorrhage $9.1 \%$ vs $19.5 \%, \mathrm{P}<0.003)$.

\section{Discussion}

The frequency of prematurity induced for severe preeclampsia was $46.2 \%$. It is higher than that reported by the WHO that was 40\% in 2013 [8]. This difference 
could be explained by the lack of regular monitoring of prenatal consultation in our communities. The same reasons are incriminated for the results found by Diguisto et al. [9] who report that $2.5 \%$ of these births occurred after a tripping or caesarean section before labor.

Our frequency is lower than that reported by Nvondo [10] in Cameroon which noted a rate of $65 \%$. This difference could be explained by the fact that in our study we excluded all the other pathologies as well as all the other circumstances which can lead to prematurity (the PRM, the malaria, the urinary infection, multiple pregnancies...).

Table 3. Neonatal outcome of severe preeclampsia.

\begin{tabular}{ccccccccc}
\hline $\begin{array}{c}\text { Neonatal } \\
\text { Complications }\end{array}$ & Premature $\geq 34$ WA & Premature $<34$ WA & \multicolumn{2}{c}{ Total } & P \\
\cline { 2 - 6 } & Number & $\%$ & Number & $\%$ & Number & $\%$ & \\
\hline Neonatal Infection & 114 & 49.4 & 47 & 27.8 & 161 & 40.3 & $<0.001$ \\
Respiratory Distress & 71 & 30.7 & 67 & 39.6 & 138 & 34.5 & $<0.05$ \\
Neonatal death & 39 & 16.9 & 67 & 39.6 & 106 & 26.5 & $<0.001$ \\
NN Hypoglycemia & 51 & 22.1 & 34 & 20.1 & 85 & 21.3 & 0.365 \\
CMH & 21 & 9.1 & 33 & 19.5 & 54 & 13.5 & $<0.003$ \\
NN Icterus & 4 & 1.7 & 2 & 1.2 & 6 & 1.5 & 0.497 \\
\hline
\end{tabular}

In our series, $95.2 \%$ of the indications of onset were of maternal origin (SPE, eclampsia, RPH and eclamptic prodromes) versus $4.8 \%$ fetal origin (CFD). This result is contrary to that found by Fournier [8] where $51 \%$ of indications were of maternal origin against $41 \%$ of fetal origin and $8 \%$ of mixed origin. This difference could be explained by the fact that the socio-economic level is very low in our environment, the recording of the fetal heart rate is not done as expected due to lack of financial means and/or apparatus equipped with option Doppler ultrasound

In our study, premature neonates had neonatal infection, respiratory distress and neonatal death complications in $40.3 \%, 34.5 \%$ and $26.5 \%$, respectively. Comparing the group of pregnant women who gave birth prematurely from 34 WA who gave birth before $34 \mathrm{WA}$, only neonatal infection was significantly more common in the first group $(49.4 \%$ vs $27.8 \%, \mathrm{P}<0.001)$ while neonatal complications significantly more frequent in the second group were respiratory distress (39.6\% vs 30.7\%: $\mathrm{P}<0.05$ ), neonatal death (39\% vs $16.9 \%$ : $\mathrm{P}<0.001$ ) and $\mathrm{CMH}(19.5 \%$ vs $9.1 \%, \mathrm{P}<0.001)$. This result is similar to that found by Hilal et al. [2] who noted that respiratory distress had a frequency of $38 \%$.

Neonatal death was estimated at $26.5 \%$ in our study. This frequency is close to one found by Tchaoun et al. [11] which was $28 \%$.

\section{Conclusions}

The frequency of induced prematurity was $4.2 \%$ of births and $46.2 \%$ in cases of 
SPE; induced Prematurity for SPE avoids in utero death, exposes newborns to the complications of prematurity: The main indications are the persistence of high blood pressure while HRP was the most frequent indication in the group of pregnant women having given birth before 34 weeks; "the neonatal outcome was poor with $26.5 \%$ of deaths due to neonatal infection, respiratory distress and metabolic disorders (hypoglycemia); premature infants who were born from 34 WA had more neonatal infection than those before 34 WA while those born before $34 \mathrm{WA}$ had more respiratory distress, neonatal death and $\mathrm{CMH}$.

Neutropenia, sepsis and prolongation of the duration of ventilation could not be observed in our due to the lack of holistic management in our setting.

Our study shows that the neonatal prognosis is poorer for newborns before 34 WA, hence the advantage of prolonging the pregnancy until at least $34 \mathrm{WA}$ if the maternal-fetal condition allows it.

\section{Author's Contributions}

All the authors contributed from the conception to the final writing of the article.

\section{Acknowledgements}

The authors thank the Heads of Service of the four maternities concerned for the facilities granted for the data collection as well as Dr. Charles UMESUMBU SHAKU for the English translation.

\section{Conflicts of Interest}

The authors declare no conflicts of interest regarding the publication of this paper.

\section{References}

[1] Ancel, Y. (2010) National Epidemiological Study for Enhanced Knowledge of Care and Subsequent Development of Very Premature Children. Epipage, 2, 5-7.

[2] Ozkan, H., Cetinkaya, M. and Koksal, N. (2012) Increased Incidence of Bronchopulmonary Dysplasia in Pretem Infants Exposed to Preeclampsia. The Journal of Maternal-Fetal \& Neonatal Medicine, 25, 2681-2685. https://doi.org/10.3109/14767058.2012.708371

[3] Ravi, T., Henning, H., Wiebecke, S., Bernhard, R., Tuelay, C., Karumanchi, A., et al. (2016) Removal of Soluble Fms-Like Tyrosine Kinase-1 by Dextran Sulfate Apheresis in Preeclampsia. Journal of the American Society of Nephrology, 27, 903-913. https://doi.org/10.1681/ASN.2015020157

[4] Cetinkayo, M., et al. (2010) Neonatal Outcomes of Premature Infant Born to Preeclamptic Mothers. The Journal of Maternal-Fetal \& Neonatal Medicine, 23, 425-430. https://doi.org/10.3109/14767050903184173

[5] Jelin, A.C., Chengy, W., Shaffer, B.L. and Kairel, A. (2010) Early Onset PE and Neonatal Outcomes. The Journal of Maternal-Fetal \& Neonatal Medicine, 23, 389-392. https://doi.org/10.3109/14767050903168416

[6] Bosso, O. (2015) Tendances dans la survie fotale et infantile après prééclampsie. 
JAMA, 296, 1357-1362.

[7] Shrestha, S., Paudel, S., Parajuli, P. and Khagi, B.R. (2017) Neonatal Outcome of Mothers with Pregnancy Induced Hypertension in Antenatal Ward of Kathmandu Medical College and Teaching Hospital. Birat Journal of Health Sciences, 2, 255-259. https://doi.org/10.3126/bjhs.v2i3.18937

[8] Fournier, P. (2010) rématurité spontanée ou induite, quelle influence sur l'avenir du nouveau-né. Gynecology and Obsetrics, 34, 1-2.

[9] Weymuller, V., Diguisto, C., Guellier, C. and Perrotin, F. (2016) Practice Indicated Preterm Birth in a Type 3 Maternity. Journal de Gynécologie Obstétrique et Biologie de la Reproduction, 45, 724-730. https://doi.org/10.1016/j.jgyn.2015.08.012

[10] Nvondo, N. (2016) Facteur de risque et devenir hospitalier des nouveau-nés prématurés à l'hôpital Gynécologique et Pédiatrique de Yaoundé. Journal de Pédiatrie et de puériculture, 23, 67.

[11] Tchaoun, B.A., Salefou, K., Hounkpure, F.M. and Chlobé, M. (2012) Prise en charge de la prééclampsie sévère dans l’hôpital Universitaire de Parakou. Vol. 17, No. 2. 